\title{
On-Ground Characterization of the SMOS Payload
}

\author{
Ignasi Corbella, Senior Member, IEEE, Francesc Torres, Senior Member, IEEE, \\ Nuria Duffo, Member, IEEE, Manuel Martín-Neira, Senior Member, IEEE, Verónica González-Gambau, \\ Adriano Camps, Senior Member, IEEE, and Mercè Vall-llossera, Member, IEEE
}

\begin{abstract}
The on-ground characterization of the synthetic aperture radiometer onboard the Soil Moisture and Ocean Salinity mission is described. Characterization includes basic functionality, internal calibration, thermal cycling, response to point and flat sources, self-radio-frequency interference, and others. The description of the different tests performed as well as the detailed results are provided. The results show that the instrument is very stable and has all gains and offsets consistent with the ones obtained at subsystem level. On the other hand, the phase of the visibility has a larger variation with temperature than expected, a small signal leakage from the local oscillators is present, and a small interference from the $\mathrm{X}$-band transmitter during short periods of time has been detected. The implementation of internal-calibration procedures, along with the accurate thermal characterization performed, have been used to produce highly accurate brightness-temperature values well within specifications.
\end{abstract}

Index Terms-Calibration and characterization, interferometric aperture synthesis, microwave radiometry.

\section{INTRODUCTION}

$\mathbf{T}$ HE SOIL Moisture and Ocean Salinity (SMOS) mission is a European Space Agency (ESA) mission designed to provide global maps of soil moisture over land and sea surface salinity over oceans [1]-[3]. Its motivation, goals, and main technical requirements and description can be found in a series of articles recently published in a special issue of the IEEE Transactions on Geoscience and Remote SENSING devoted to SMOS. In particular, the overall mission

Manuscript received July 31, 2008; revised October 21, 2008, December 2, 2008, January 8, 2009, and February 2, 2009. First published April 21, 2009; current version published August 28, 2009. This work was supported by the European Space Agency and by EADS-CASA Space Division under ESTEC Contract 17950/03/NL/FF-SMOS and in part by the Spanish Ministry of Science and Innovation under Projects TEC2005-06863-C02-01/TCM and TEC2008-06764-C02-01.

I. Corbella and F. Torres are with the Remote Sensing Laboratory, Department of Signal Theory and Communications, Universitat Politècnica de Catalunya, 08034 Barcelona, Spain, and also with the SMOS Barcelona Expert Centre on Radiometric Calibration and Ocean Salinity, 08003 Barcelona, Spain (e-mail: corbella@tsc.upc.edu; xtorres@tsc.upc.edu).

N. Duffo, A. Camps, and M. Vall-llossera are with the Remote Sensing Laboratory, Department of Signal Theory and Communications, Universitat Politècnica de Catalunya, 08034 Barcelona, Spain (e-mail: duffo@tsc.upc.edu; camps@tsc.upc.edu; merce@tsc.upc.edu).

M. Martín-Neira is with the European Space Research and Technology Centre, European Space Agency, 2200 AG Noordwijk, The Netherlands (e-mail: Manuel.Martin-Neira@esa.int).

V. González-Gambau is with the Passive Remote Sensing Group, Remote Sensing Laboratory, Department of Signal Theory and Communications, Universitat Politècnica de Catalunya, 08034 Barcelona, Spain, and also with the SMOS Barcelona Expert Centre on Radiometric Calibration and Ocean Salinity, 08003 Barcelona, Spain (e-mail: veronica.gonzalez@tsc.upc.edu).

Color versions of one or more of the figures in this paper are available online at http://ieeexplore.ieee.org.

Digital Object Identifier 10.1109/TGRS.2009.2016333 is described in [4]. According to this reference, the required spatial resolution is $50 \mathrm{~km}$, the measurement accuracy is $4.1 \mathrm{~K}$, and the radiometric sensitivity depends on the product: $3.5 \mathrm{~K}$ for soil moisture and $2.5 \mathrm{~K}$ for ocean salinity.

Responsible for achieving these quality goals is the single payload of the mission: the Microwave Imaging Radiometer with Aperture Synthesis (MIRAS) [5], [6]. It is a Y-shaped synthetic aperture radiometer integrating a total of 69 small L-band antennas. It uses the interferometric principle to synthesize multiple narrow beams by cross-correlating the signals collected by a large number of antenna pairs [7]. The highresolution brightness-temperature image is obtained by the mathematical inversion of the measured 2-D visibility function [8]. This is a new technique for Earth observation from space and also a technological challenge. To achieve the state-of-theart requirements specified by the project science team, accurate and complex calibration procedures have been developed and implemented [9], [10], which rely on a very careful and precise on-ground characterization.

The instrument was successfully assembled by the European Aeronautic Defence and Space Company N.V. (EADS)-CASA Espacio (Spain), and it was subjected to an extensive testing process aimed at checking the hardware and software operation as well as validating calibration procedures [10] and the imaging capability. The tests included, among others, the following:

1) calibration sequences evaluation;

2) polarization check;

3) stability;

4) interelement phase retrieval;

5) correlation offset;

6) electromagnetic compatibility;

7) image validation.

The calibration sequences were evaluated by checking that all the internal switches and modes of the instrument operated correctly to produce the sequences programmed according to the calibration plan. The polarization check confirmed that the instrument was measuring the correct polarization at which it was commanded. In the stability tests, the instrument was left measuring continuously for several hours, and the outcome was recorded and analyzed. The interelement phase retrieval provided the relative phase for all baselines [11]. The correlation offset was performed to assess residual offsets due to internal leakages, and the electromagnetic compatibility tests were devoted to identify sources of radio-frequency interference (RFI) from several parts of the instrument or platform. Image validation was oriented at producing images of the constant temperature of the chamber. 


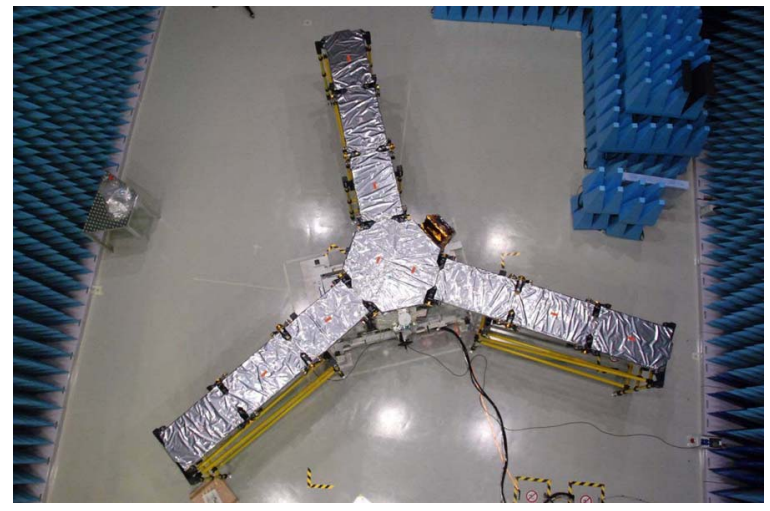

Fig. 1. SMOS payload. MIRAS fully deployed inside the Maxwell anechoic chamber at ESA-ESTEC. Courtesy of EADS-CASA Espacio.

This paper presents some of the results obtained in different testing campaigns. Section II describes the instrument, Section III presents the ground-characterization strategy, Section IV gives the results of the calibration assessment, Section V is devoted to the thermal characterization, Section VI describes the image validation results, and finally, Section VII gives the results about the RFI.

\section{INSTRUMENT}

\section{A. Hardware}

Fig. 1 shows a photograph of MIRAS fully deployed inside the "Maxwell" anechoic chamber at the ESA's European Space Research and Technology Centre (ESTEC) in Noordwijk (The Netherlands). Each arm has an overall length of about $4 \mathrm{~m}$ from the center of the structure, including part of the hexagonal "hub" and three segments. Although not seen due to the radome covering the payload, each segment has six equally spaced dualpolarization small antennas, and the hub has a total of 15 antennas of the same design [6]. Each antenna is, in turn, connected to a corresponding L-band low-noise receiver called "LIghtweight Cost-Effective Front-end" (LICEF), each one having an input switch to select one of two orthogonal polarizations. Three of the antennas in the hub are not assigned to LICEF's, but connected instead to full-polarimetric noise-injection radiometers (NIRs) used as reference receivers [12]. To perform internal calibration, a noise distribution network (NDN) and internal noise sources are also included in the instrument [13]. A summary of the main components is as follows:

1) 69 small antennas (66 in LICEF and 3 in NIR);

2) 72 front ends (66 for LICEF and 6 for the two channels of the three NIRs);

3) 2346 baselines ( 2145 between LICEFs, 198 between NIR and LICEF, and 3 between NIRs);

4) 10 noise sources with associated distribution network [three per arm (1-12) and one in the HUB (1-18)];

5) 121 temperature sensors ( 72 in LICEFs, 31 in calibration system, and 18 in NIR).

This hardware produces the following signals:

1) 72 power measurement system (PMS) voltages;

2) $2556 \times 2$ digital correlator counts (real and imaginary);
3) 6 NIR Dicke pulse fractions;

4) control signals for switches and instrument modes;

5) temperature sensor redouts;

These signals are converted to numerical information and saved as binary files in the onboard computer. At selected times during nominal operation, all data are downloaded to the ground station via an X-band transmitter. During the characterization tests, this operation was performed exactly as expected in flight. A simple X-band antenna and front end was used to collect the signal transmitted by the payload, and its output was redirected to the computers where the processing software was installed.

\section{B. Software}

All data were processed using the software tool described in [14], which provides results in almost real time. The software reads the raw data received from the payload X-band transmitter and automatically computes a number of data products including the calibrated visibility, system temperatures, antenna temperatures, calibration parameters, NIR outputs, etc. All are available to the user in data files and in graphics format in the screen. The tool has a user-friendly graphics interface that allows selecting specific data according to different parameters. In this way, it is very simple to visualize any selected parameter and have a quick feedback of the instrument behavior.

The overall processing is organized in several steps, and intermediate results are saved in a disk so as to allow reprocessing at any time without having to do it from the beginning. The first step classifies the input data stream (level 0 ) according to measurement type (correlation, PMS, temperatures, control signals, etc.). The result is used in the second step as input for processing to a higher level, involving the correction of the quadrature error and comparator offset, obtaining, as result, the quadraturecorrected normalized correlation $M_{k j}$ [9], [15]. The calibrated visibility (level $1 \mathrm{~A}$ ) is computed in the next step after denormalization using the system temperatures calibrated with a four-point two-level noise injection [9], [16]. This calibrated visibility is used as input for the image reconstruction process, resulting in the brightness temperature at the antenna reference plane (level 1B). Only a preliminary method (inverse Fourier transform) [17] was used since the objective of the tests was oriented more to the payload itself than to processing to higher levels.

\section{Ground-Characterization Strategy}

One of the main objectives of the ground characterization was to check the correct implementation of the internal calibration as well as the corresponding processing of the resultant data. The goal was to show that the instrument could be calibrated as predicted and to produce brightness-temperature images with the required accuracy. Another objective was the determination of the sensitivity coefficients for calibration parameters, needed to correct the measurements between calibration events and the interelement phase, used in the inversion procedures. Finally, possible sources of RFI were identified in 
dedicated experiments. To achieve these objectives, the ground characterization of MIRAS was performed in four steps.

1) Preliminary tests made at the EADS-Casa Espacio clean room in January 2007, aimed at performing basic functionality tests, assessing the internal-calibration algorithms, and debugging the onboard and ground data processing software. In these tests, the instrument was folded, and the input switch to antenna was disabled, so that only measurements with noise injection were possible.

2) Thermal characterization at the ESA-ESTEC Large Space Simulator (LSS) in April 2007, aimed at characterizing the variation of calibration parameters and overall performance with respect to changes in physical temperature. In these tests, the instrument was fully deployed inside the LSS, and the temperature and pressure were varied and monitored. As in the previous case, only the measurement of injected noise was performed.

3) Image validation tests at the ESA-ESTEC Maxwell anechoic chamber (May-June 2007), aimed at validating the procedures for image reconstruction, as well as measuring the interelement phase [11], instrument stability, and self-RFI. The instrument was fully deployed inside the chamber, and measurements were performed for the first time with signals from the antennas.

4) Platform integration tests, oriented to check the compatibility of the payload and the platform after the integration of both and to investigate on the residual correlation offsets. These tests were performed at Thales Alenia Space in Cannes, France, in April 2008 with the instrument fully deployed inside an anechoic chamber.

The following sections give some details on all these tests and results obtained.

\section{INTERNAL-CALIBRATION AsSESSMENT}

A general description of the MIRAS in-orbit calibration can be found in [10]. It includes both external calibration, performed by turning the payload to measure the cold sky, and internal calibration, consisting of periodically injecting two levels of noise to all receivers. External calibration is used to get the absolute accuracy in brightness temperature and to characterize the instrument in terms of "flat-target response" [18]. Internal calibration is used to track the thermal variation of the different components by periodically measuring the relevant individual receiver parameters, such as gains and offsets. The internal-calibration process is structured in several predefined sequences that have been programmed in the onboard software. They are defined as "long calibration," "short calibration," and "local-oscillator phase tracking." Both external and internal calibrations will be performed regularly at a rate to be defined during the commissioning phase.

\section{A. Overview}

Fig. 2 shows a block diagram of the internal-calibration approach [9]. Two levels of noise (named "Hot" and "Warm") are sequentially injected to the receivers' inputs as well as to the

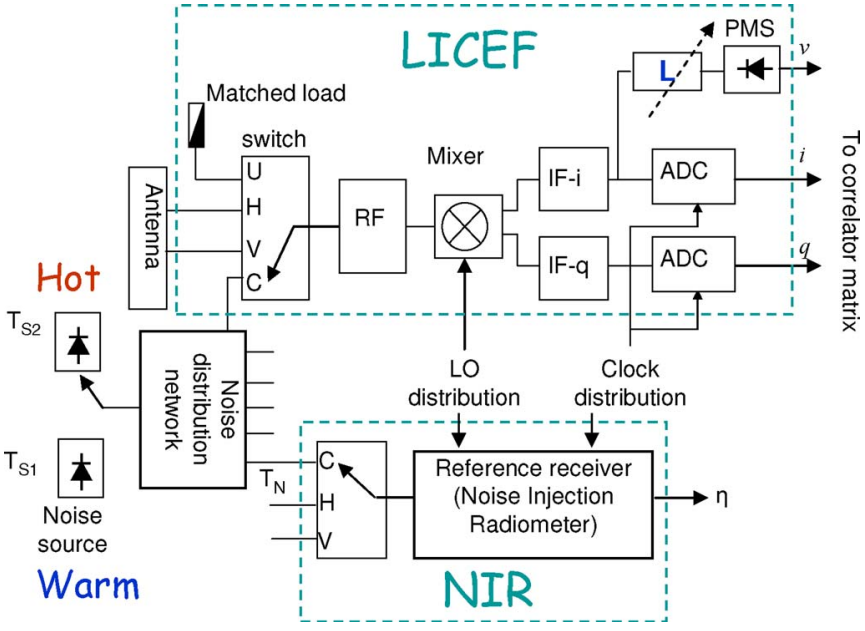

Fig. 2. Block diagram of the MIRAS internal calibration.

NIR's. The noise temperatures at the NIR's inputs are retrieved from their outputs (fraction of Dicke cycle) using factory calibration parameters and the procedures described in [12]. These temperatures are transferred to all LICEF's inputs using the S-parameters of the NDN, independently characterized by the Helsinky University of Technology [13]. An internal attenuator at intermediate frequency in all receivers can be set to two different values providing two additional levels at the PMS diodes. After applying the procedures of [9], all PMS gains $\left(G_{k}\right)$ and offsets $\left(O_{k}\right)$, as well as all correlator complex gains $\left(G_{k j}\right)$, are retrieved. Having these three parameters, the calibrated visibility during normal measurement can be computed as

$$
V_{k j}=\frac{M_{k j} \sqrt{T_{\mathrm{sys}_{k}} T_{\mathrm{sys}_{j}}}}{G_{k j}}
$$

where the system temperatures are estimated using the PMS voltages $v_{k}$ with

$$
T_{\mathrm{sys}_{k}}=\frac{v_{k}-O_{k}}{G_{k}} .
$$

The availability of an independent characterization of all LICEFs made by the manufacturer (MIER Comunicaciones, Barcelona, Spain) was used to assess the consistency of the PMS internal calibration [19]. For all PMS units fed by the same noise source, the difference in system temperatures at their inputs between Hot and Warm injections must be the same except for the NDN unbalance. This is true because the differential measurement removes the individual noise contribution from each LICEF and from the NDN itself. In turn, the network unbalance can be compensated since it has been thoroughly characterized on ground in terms of S-parameters [13]. The remaining differences between differential measurements are indicators of the consistency of all the calibration procedures, including the characterization of the distribution network and individual receivers.

A "self-consistency tool" was designed in order to give, for a set of LICEF units, the fractional deviation in the magnitude measured by each PMS with respect to the mean of all units. Since the different noise injection levels are equalized and the NDN imbalance is corrected, this deviation is an estimator of 

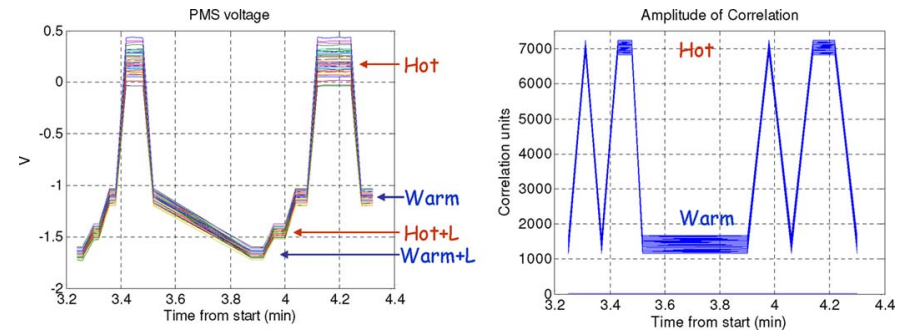

Fig. 3. (Left) PMS voltages and (right) correlations during calibration sequences.
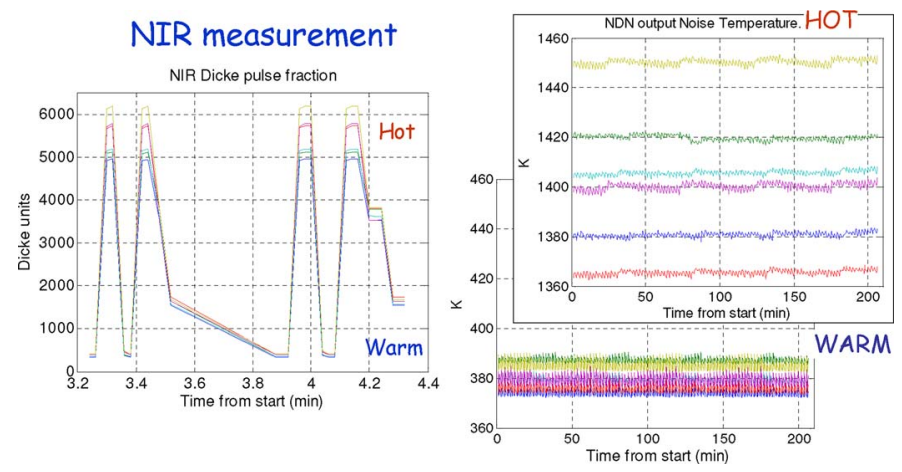

Fig. 4. (Left) NIR Dicke cycle during calibration sequences. (Right) Hot and Warm injection temperatures retrieved from NIR data.
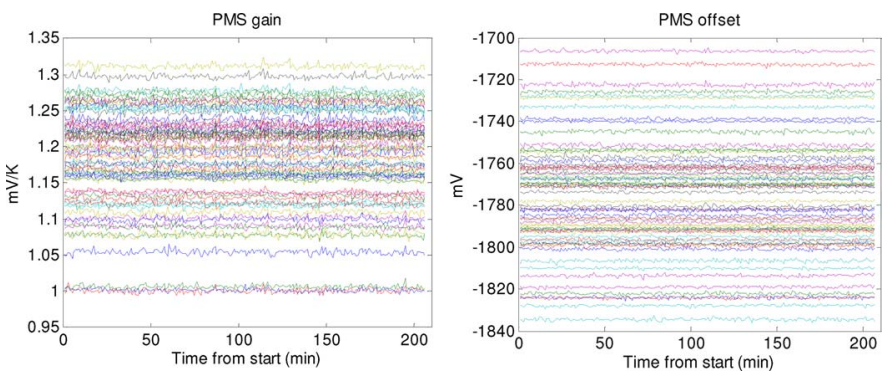

Fig. 5. PMS gain and offset measured from internal calibration.

PMS gain uncertainty and, therefore, of visibility amplitude errors.

\section{B. Results}

Fig. 3 shows the measured voltages and correlations during two sequences of calibration. The four levels are clearly visible in the PMS voltages and the two levels in the correlation plot. The "correlation units" are defined as normalized values multiplied by $10^{4}$. Fig. 4 (left) shows the corresponding measurements of the NIR, expressed in fractions of the Dicke cycle multiplied by $10^{4}$, which are called "Dicke units." The two levels, Hot and Warm, are also seen. The corresponding noise temperatures at the NIR input are shown at the right of Fig. 4. The different values correspond to differences in the S-parameters of the corresponding branch of the NDN to each NIR.

Fig. 5 shows the results of PMS gain and offset obtained during a sequence of 198 repeated calibration sequences. These values are consistent with the ones obtained during the manufacturing of the individual receivers, and they show high stabil-
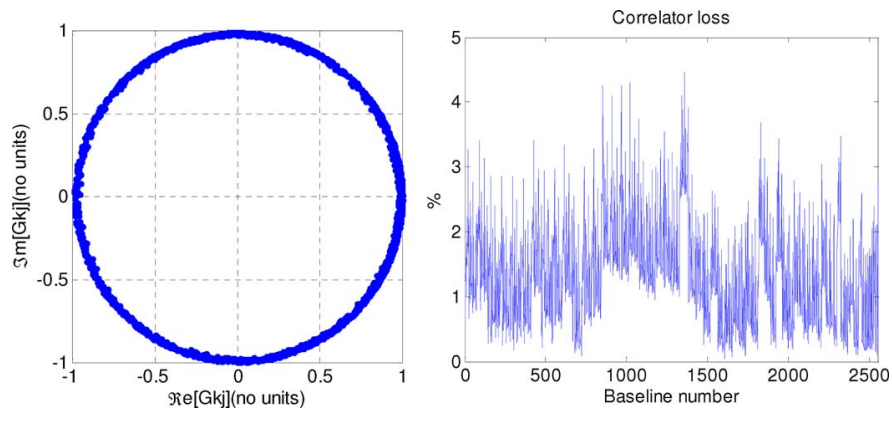

Fig. 6. Fringe washing function at the origin measured from internal calibration. (Left) Complex values. (Right) Correlation loss defined as $\left(1-\left|G_{k j}\right|\right) 100$.

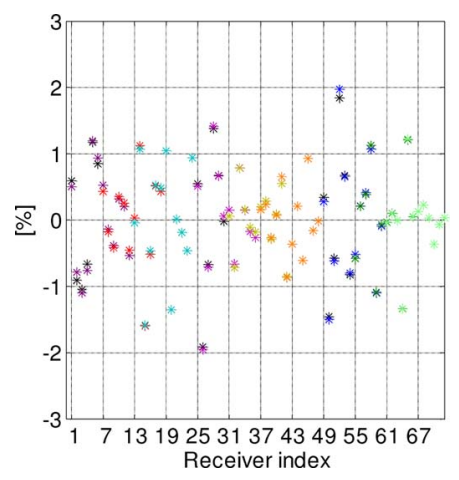

Fig. 7. Relative error in system temperature retrieval computed using the consistency tool.

ity, with uncertainties due to limited integration time according to the theoretical expectations.

The measured correlator complex gain corresponding to all baselines for the same 198 calibration sequences is shown in Fig. 6 (left). Note that, as expected, all amplitudes are approximately unity, and the phase is randomly distributed from 0 to $2 \pi$. It should be recalled that, for a given baseline, the phase of $G_{k j}$ is equal to the difference between the phases of the overall frequency responses of the two receivers forming the baseline. These individual phases include the phase added by the local oscillator. The amplitude of the complex gain $G_{k j}$, also called "correlation efficiency," is an estimator of the receivers' frequency response dispersion. It is shown in the plot at the right of Fig. 6 in terms of "correlation loss" defined as $\left(1-\left|G_{k j}\right|\right)$ 100 . The high degree of similarity of all receivers results in this parameter being about $1.5 \%$ in average with a maximum of $4 \%$ in a few baselines. This good result is a consequence of the tight specification of the filter frequency response similarity [20].

Fig. 7 shows the output of the consistency tool as relative error in amplitude calibration. The error presents a random distribution with low dispersion (around 4\% peak-to-peak). It includes the following: 1) error and drift from factory PMS calibration parameters; 2) compensation for temperature PMS drift; and 3) S-parameter error after temperature correction. As a consequence, the error that can be assigned to S-parameter uncertainty is quite low, well below system requirements. These results are very promising since amplitude errors are already set below $1 \%(1 \sigma)$ and keep a margin for additional improvement once the reference radiometers (NIR) are calibrated in orbit by means of the deep sky views. 


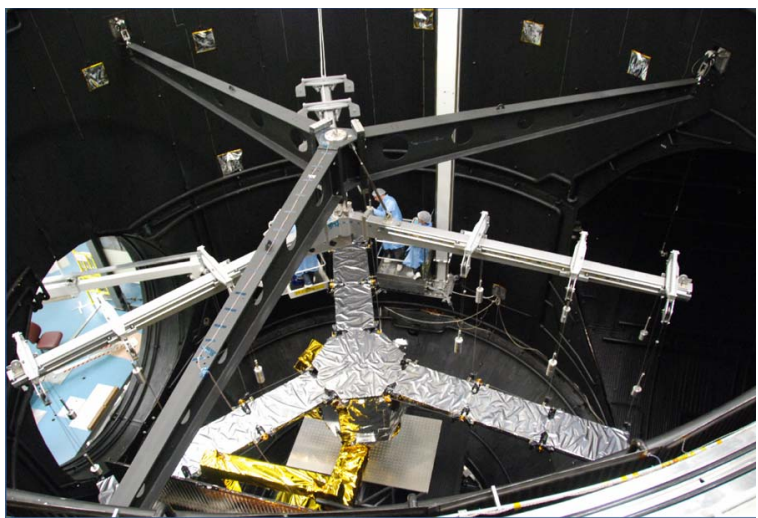

Fig. 8. MIRAS deployed inside the LSS in ESA-ESTEC. Courtesy of EADSCASA Espacio.

\section{THERMAL CHARACTERIZATION}

Thermal characterization was carried out at the LSS in ESAESTEC, which has the capability of setting the ambient temperature and pressure to values emulating the space conditions. Fig. 8 shows the payload fully deployed inside this installation.

\section{A. Approach for Thermal Characterization}

The physical temperature variation of each LICEF is controlled by the thermal control subsystem based on a passive design (insulation blankets, black paint, etc.) supported by an active system of heaters [6]. The goal is to maintain a constant operational temperature of $22{ }^{\circ} \mathrm{C}$ for each LICEF, minimizing the spatial and temporal gradients among them. The constraints of the design result in a maximum temperature difference between receivers of $5{ }^{\circ} \mathrm{C}-7{ }^{\circ} \mathrm{C}$ with an orbital stability of about $1.3{ }^{\circ} \mathrm{C}$. Over $80 \%$ of the receivers are expected to show a gradient of less than $2{ }^{\circ} \mathrm{C}$ [10]. Variations of even a few degrees in the physical temperature of the receivers can have a significant impact on the brightness temperature retrieval, and therefore, the ground processing must include a correction based on a precise on-ground thermal characterization. The physical temperature of each LICEF receiver is monitored by a thermistor and the data included in the telemetry stream. Each NIR is monitored using eight thermistors in order to allow accurate corrections on ground.

The thermal characterization follows the methodology proposed in [16]. All PMS gains and offsets are characterized by sensitivity coefficients derived by linear fit from measurements in a limited temperature range around the operational point. The sensitivity parameters obtained have been included in the instrument database to be used during flight for estimating the gain and offset at a given working temperature $T$ using

$$
\begin{aligned}
& G(T)=G\left(T_{\text {cal }}\right)+S_{G}\left(T-T_{\text {cal }}\right) \\
& O(T)=O\left(T_{\text {cal }}\right)+S_{O}\left(T-T_{\text {cal }}\right)
\end{aligned}
$$

where $S_{G}$ and $S_{O}$ are the sensitivity coefficients for the PMS gain $(G)$ and offset $(O)$, respectively, and $T_{\text {cal }}$ is the physical temperature at the time of calibration. The aforementioned equations are computed individually for each one of the 72 receivers in the payload. The sensitivity coefficients will be updated on-flight from measurements made in the long

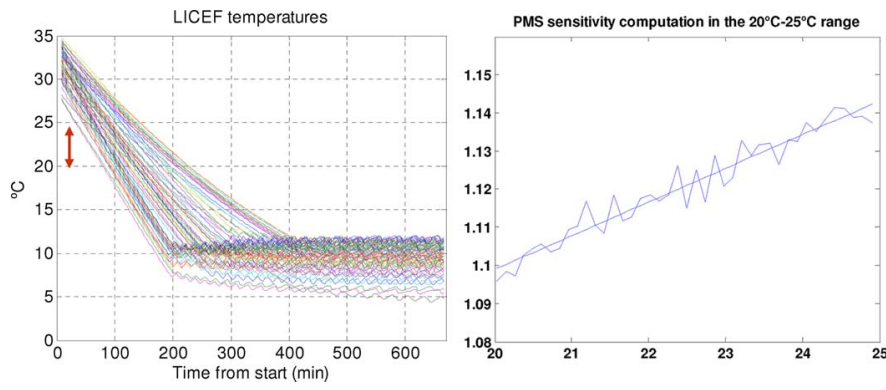

Fig. 9. (Left) LICEF's physical temperature during the test. (Right) Example of the gain variation of a receiver with respect to temperature.
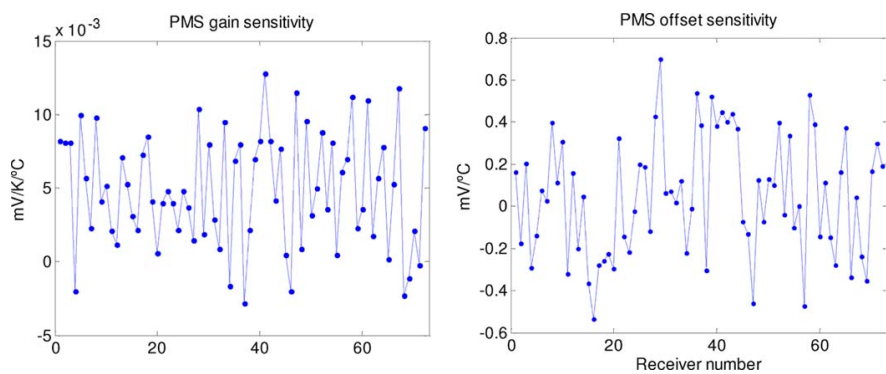

Fig. 10. PMS gain and offset sensitivities derived from the tests.

calibration operations, carried out during a whole orbit and taking advantage of the temperature variation along one orbit.

\section{B. Results}

Fig. 9 shows the measured physical temperature of all LICEFs during a large thermal swing from ambient to a few degrees celsius. The double arrow shows the range used to derive the sensitivity coefficients. The linear fit of the gain for a particular receiver is shown in the plot on the right. The retrieved sensitivities for PMS gains and offsets of all receivers are shown in Fig. 10. These results are compatible with the characterization performed at subsystem level [16]. Considering that the average gain and offset are about $1 \mathrm{mV} / \mathrm{K}$ and $-1700 \mathrm{mV}$ (see Fig. 5), it follows that the receivers are extremely stable in temperature.

The variation of the phase of the correlator gain $G_{k j}$ with respect to temperature was found to be much more complex than initially found in [16]. For two receivers sharing the same local oscillator, this phase roughly follows the average physical temperature of the two receivers involved, as expected. However, in baselines formed by receivers having different local oscillators, the individual phase of each receiver follows the temperature of its own local oscillator, giving, as a result, a phase of $G_{k j}$ not correlated with the temperature of the receivers themselves. This is shown in Fig. 11. On the left, the phase of $G_{k j}$ for a given baseline is shown, along with the physical temperature of the receivers and its mean (solid black line). There is no clear correlation between the phase and the temperature. On the right, the individual phases of the two receivers is shown along with the temperature of the corresponding local oscillators. The correlation between each phase and the local-oscillator temperature is clear. This result has led us to modify the initial calibration requirements so as to include the local-oscillator phase tracking calibration sequence 

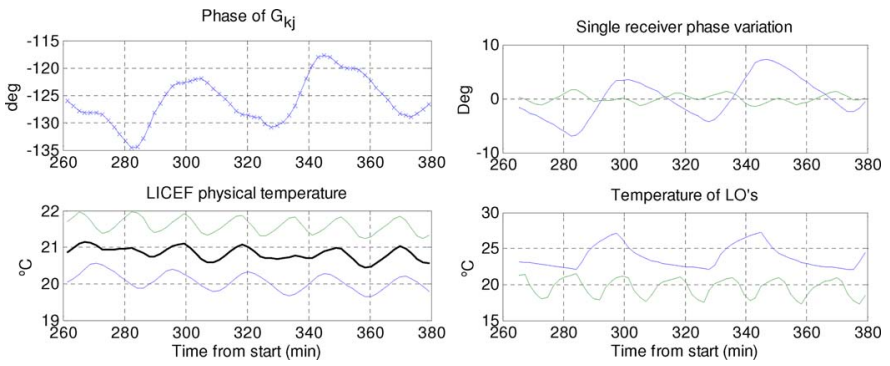

Fig. 11. Correlation phase variation due to temperature. The thin green and blue lines correspond to two different receivers or the corresponding local oscillators, respectively. The solid black line at the left bottom plot is the average of (in green and blue) both temperatures.

(see Section III). This sequence will provide frequent phase calibration during the nominal operation of the instrument.

\section{IMAGE VALIDATION}

Image validation tests were carried out at the ESA Maxwell anechoic chamber. Long series of measurements - up to $12 \mathrm{~h}$ with the chamber "empty" (i.e., without any active source on) at constant temperature were carried out in order to check instrument stability and to accurately measure the emptychamber correlation with large integration time. Furthermore, experiments including active sources at a known location were performed to assess the polarization switching consistency for both dual- and full-polarization modes [21] and also to measure the antenna interelement phases.

\section{A. Theoretical Visibility}

An anechoic chamber at a constant temperature is a completely unpolarized target having equal brightness temperatures from any direction. The visibility that a baseline should measure for such a "flat target" is given by [8]

$$
V_{k j}=\left(T_{\mathrm{ch}}-T_{r_{k j}}\right) F T R_{k j}
$$

where the subscripts $k$ and $j$ refer to the receiver numbering, $T_{\mathrm{ch}}$ is the physical temperature of the chamber, $T_{r_{k j}}$ is the average between the physical temperatures of the receivers involved, and $F T R_{k j}$ is the flat-target response of that particular baseline [18]. In normal operation, it will be measured during sky looks while in external calibration. Alternatively, it can be analytically computed from the measured antenna patterns using [8], [17]

$$
F T R_{k j}=\frac{1}{\sqrt{\Omega_{k} \Omega_{j}}} \iint_{4 \pi} \vec{F}_{k}(\theta, \phi) \cdot \vec{F}_{j}(\theta, \phi) \tilde{r}_{k j}\left(\frac{\Delta r}{c}\right) e^{j k \Delta r} d \Omega
$$

where $\vec{F}$ is the field antenna pattern (a complex vector in general) and $\tilde{r}_{k j}$ is the normalized fringe washing function. Other parameters in the equation are the following: $\Omega$ as the antenna solid angle, $\Delta r$ as the incremental distance from a source point to each antenna, $c$ as the velocity of light, and $k$ as the wavenumber. When the whole instrument is placed inside an anechoic chamber, the expected visibility for all baselines is very small because $T_{\mathrm{ch}}-T_{r_{k j}}$ in (4) is also small.
To measure the residual correlation offset due to signal leakage through the instrument mechanical structure, the payload was left measuring continuously for about $3.3 \mathrm{~h}$ in the socalled "U-mode," in which all receivers were connected to independent matched loads. For any receiver, the measured physical temperature variation during the duration of the test was within $0.03{ }^{\circ} \mathrm{C}$ peak to peak. In these conditions, the theoretical correlation measurement should have zero mean and standard deviation given by $1 / \sqrt{B \tau_{\text {eff }}}=0.028 \times 10^{-4}$ with $\tau_{\text {eff }}$ as the total effective integration time due to the use of digital correlators [22].

Brightness-temperature images were generated by inverting the calibrated visibilities acquired during the empty-chamber measurements. The method implemented consists of an inverse Fourier transform with the compensation of the obliquity factor and the average antenna power pattern [17]

$$
T_{B}(\xi, \eta)=\mathcal{F}^{-1}[V(u, v)] \frac{\Omega \sqrt{1-\xi^{2}-\eta^{2}}}{\left|\bar{F}_{n}(\xi, \eta)\right|^{2}}+T_{r}
$$

To further assess the performance of amplitude calibration, the absolute brightness temperature of the chamber was estimated from PMS measurements using the one-point calibration approach [23]. This is an alternative of using the internal calibration and is based on a classical two-load method in which one of them is an internal matched resistor at known temperature, which is available in all LICEFs.

For the tests including a probe emitting noise, the visibility was theoretically estimated using [11]

$$
V_{k j}=\left(T_{s}-T_{\mathrm{ch}}\right) \frac{\lambda^{2}}{(4 \pi)^{2} r_{k} r_{j}} \sqrt{\Gamma_{k} \Gamma_{j}} e^{j k \Delta r} C_{k j}+V_{0}
$$

where $T_{s}$ is the emission temperature of the source, $\Gamma$ is the product of the directivities of the probe and LICEF antennas, $V_{0}$ is the visibility of the empty chamber [equal to $V_{k j}$ in (4)], and $C_{k j}$ is the polarization mismatch coefficient of the antennas involved. This formulation was used to derive the antenna interelement phases.

\section{B. Setup}

A test jig was designed by EADS-CASA Espacio to allocate four probes, one in the center and the other three in the arms of a Y-shaped mechanical structure about half the size of MIRAS and transparent to the microwave radiation. Fig. 12 shows a photograph of this test jig installed in the ceiling of the chamber. Noise power at two levels from a common source was redirected to a particular probe by electronically controlled switches. Each probe had a single polarization antenna but it could be manually rotated to change the orientation with respect to the instrument. Tests at two different heights separated about a quarter wavelength were performed. In all cases, the relative distances and orientations of the probes were accurately measured with a laser tracker before the starting of any test. To monitor the physical temperature, three sensors were placed at two opposite corners in the ceiling of the chamber, whereas a 


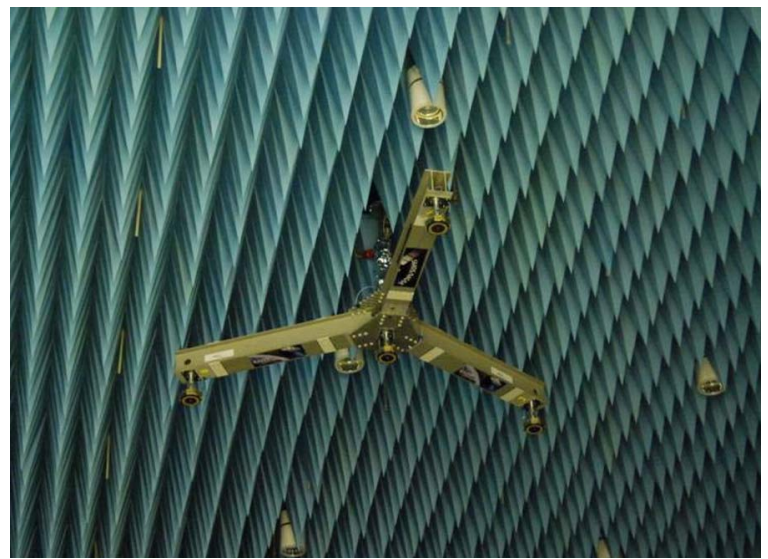

Fig. 12. Test jig with four probes in the ceiling of the Maxwell anechoic chamber at ESA-ESTEC

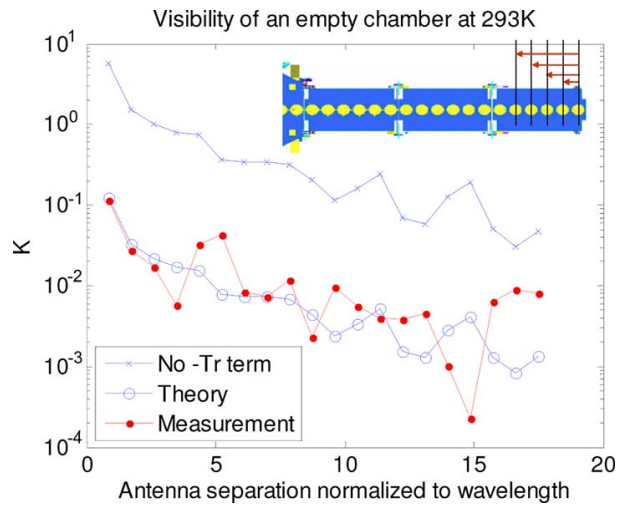

Fig. 13. Visibility of the empty chamber. Comparison between theoretical predictions and actual measurements.

third one was placed in the middle of one of the ceiling sides, at the top of one of the side walls.

\section{Results}

Fig. 13 shows the measured visibility of the empty chamber corresponding to 20 selected baselines formed by an antenna at the end of one arm and the ones of the rest of the same arm. Furthermore, shown in the figure are the theoretical predictions (4) as well as the contribution of only the thermal emission of the chamber, which is neglecting the $\left(-T_{r}\right)$ term in (4) that accounts for the interelement coupling of thermal noise. As seen in the figure, the matching between the theory and the measurements is excellent, confirming the results of [24]. The flat-target response was estimated using (5) with the antenna patterns measured by the Denmark University of Technology in the frame of the SMOS project.

Fig. 14 shows the results about the residual correlation offset. On top, the direct measurements obtained show a standard deviation of about $0.25 \mathrm{cu}$, which is much larger than expected. After correcting for the comparator offset using the technique of [15], the standard deviation becomes $0.03 \mathrm{cu}$, which is in agreement with the theoretical predictions of Section VI-A, but there is still a residual offset of about $0.2 \mathrm{cu}$. This offset was found to be produced by a truncation error in the correltors. After compensating this error using the correlations
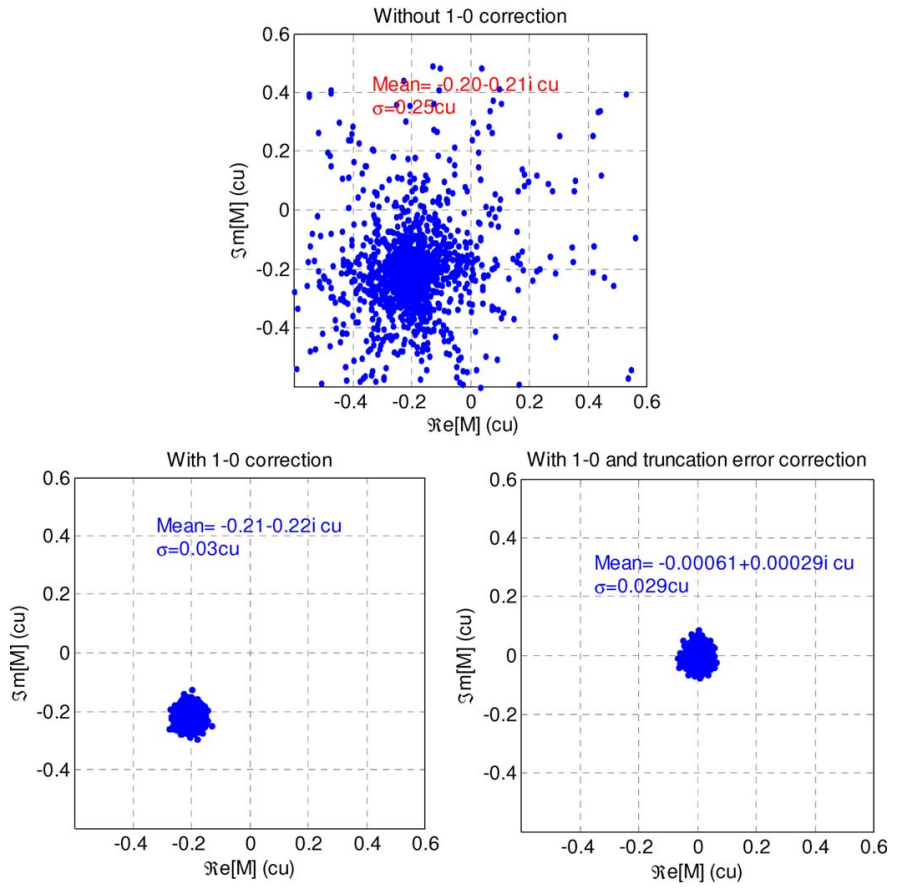

Fig. 14. Residual correlation offset of baselines not sharing a common noise source after averaging of $3.3 \mathrm{~h}$. (Top) Without 1-0 correlator offset correction. (Bottom left) With 1-0 correction. (Bottom right) With both 1-0 and truncation error correction.

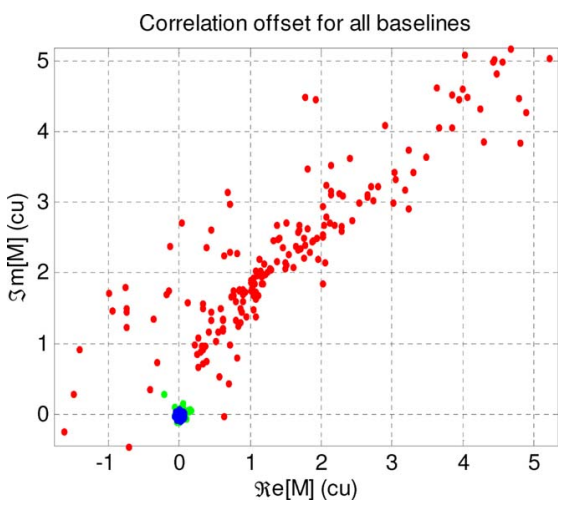

Fig. 15. Residual correlation offset of all baselines including (green) those sharing a noise source and those sharing also a common local oscillator. In this last case, the leakage produces statistically the same mean value for the real and imaginary parts, resulting in a phase at about $+45^{\circ}$.

with all ones and zeroes available in the data, the offset was reduced to a negligible value, as can be seen in the figure at the bottom right.

These results were obtained for baselines with no signal path connecting the corresponding receivers. This means not sharing a common noise source or common local oscillator. For the 612 baselines formed by receivers connected through an NDN, even after careful design and having high isolation requirement, the residual offset happened to be somewhat higher. However, the most important effect was the local-oscillator thermal noise leakage. Fig. 15 shows the offset measured for all baselines. The bunch of dots close to the origin is the result shown in Fig. 14. The correlation values that lay approximately at $+45^{\circ}$ correspond to those baselines sharing the same local oscillator, which was distributed in sections of six LICEFs [6]. In this case, the leakage enters the mixer by the LO port, and 

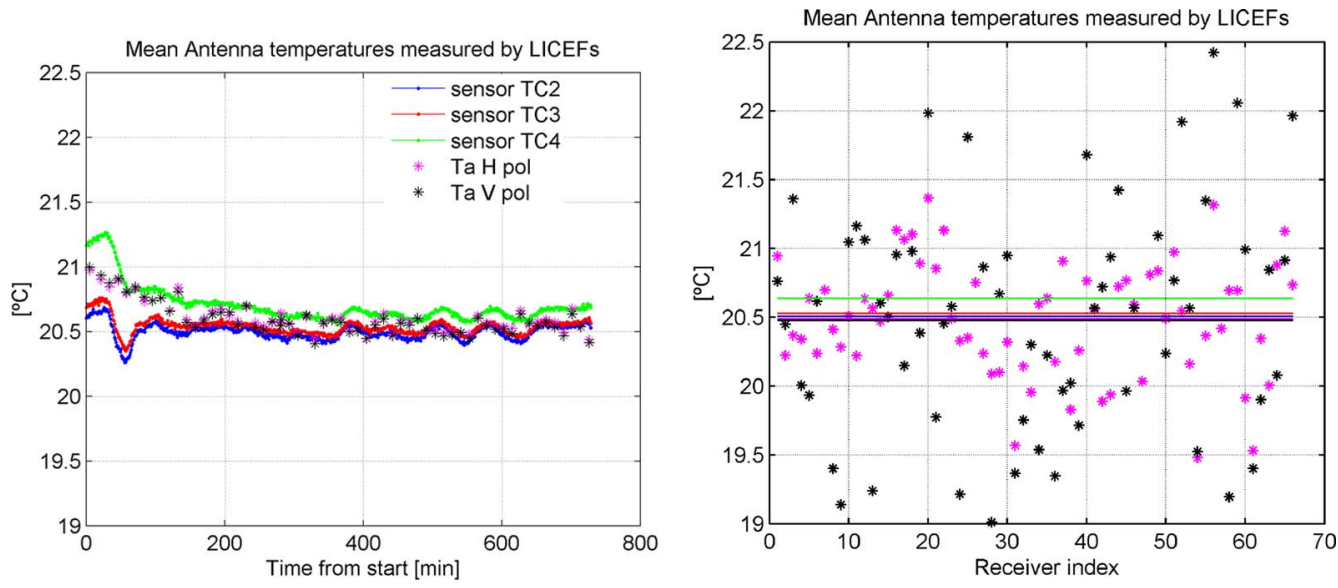

Fig. 16. Brightness temperature of the chamber measured by the LICEF PMS compared with the physical temperature measured by three thermistors.

both in-phase and quadrature channels measure the same value of correlation, with the result of having a complex correlation with a constant phase of $+45^{\circ}$. During nominal SMOS operations, the visibility offset of these baselines will be subtracted from the measured visibility. To update the offset value, the long calibration sequences include long measurements with the instrument in the already mentioned U-mode.

Fig. 16 shows the antenna temperature measured by the PMS using the one-point calibration strategy. The results are expressed in degrees celsius for comparison with the sensor readings. For each LICEF, the value used is the average of 25 consecutive measurements to reduce thermal noise below $0.04 \%$. Each point in the plot is then the average of the antenna temperature measured by all 66 LICEFs in the array (NIR were not used). This reduces systematic error (bias) and thermal noise by an additional factor larger than eight. As it can be seen, the instrument estimates the anechoic chamber temperature with high accuracy and follows its variations. Fig. 16 (right) shows a time average of the basic magnitudes regarding the full duration of the test. The mean temperature registered by the three sensors along the full test is plotted as a straight line. The horizontal axis represents each one of the 66 LICEF units in the array. Then, their antenna temperature [both horizontal $(\mathrm{H})$ and vertical $(\mathrm{V})]$ is plotted as the mean value for the whole test. It is clearly seen that each single LICEF presents some bias in the estimation of the Maxwell ceiling's brightness temperature. However, although the performance of each single LICEF is not outstanding, the mean value of the whole set of 66 receivers, both in $\mathrm{H}$ - and V-polarization, estimates the Maxwell ceiling's brightness temperature within $0.1 \mathrm{~K}$. Similar results are obtained using the antenna temperature measured by NIR [25]. It should be mentioned that, during the execution of this test, the payload was actually warming up, as can be shown in the plots of physical temperature shown in Fig. 17.

Fig. 18 (left) shows the retrieved interelement phases of all LICEFs in H-polarization using the four probes at two levels of noise, two different rotation angles, and two different heights (ten independent measurements). All measurements are very consistent with each other, thus providing a good estimation of the antenna interelement phases. The average of all measurements for each antenna is shown at the right as well as the corresponding standard deviation of the error, which is about

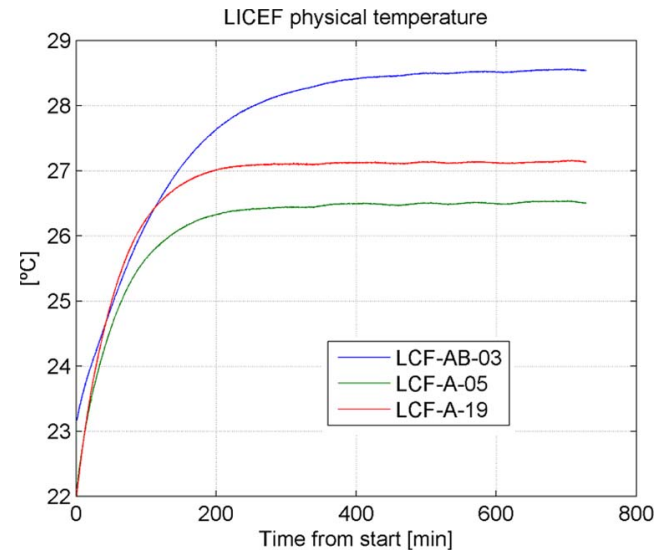

Fig. 17. Physical temperature of some LICEF during the test in Fig. 16.
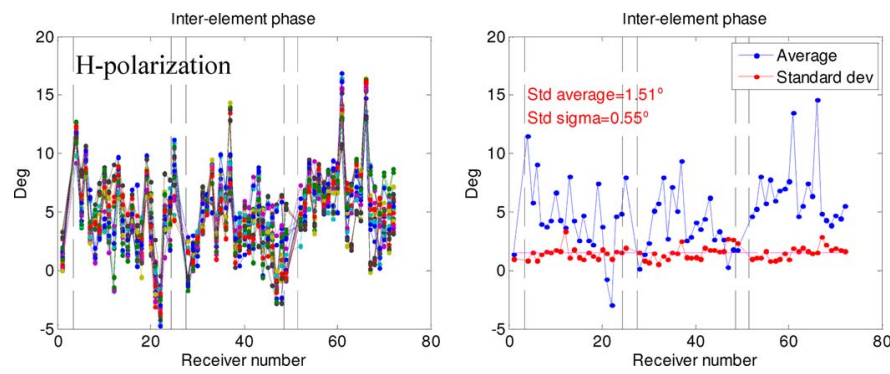

Fig. 18. Interelement phase obtained from point source measurements [11] (Left) Results of all retrievals with different probes, power levels, and orientations. (Right) Average and standard deviation of all measurements.

$1.5^{\circ}$. Taking into account that this is the result of performing ten independent measurements, the accuracy of the mean value is about $\sigma=0.5^{\circ}$. Results for V-polarization are similar. NIR antennas are not included in the figure since they have much larger values of phase due to the larger length of the cables used to connect the antennas to the front ends.

Fig. 19 shows the result of inverting the empty chamber visibility using (6) for H-polarization. As expected, a constant value of brightness temperature is obtained. The spatial standard deviation computed in the circle shown is about $0.33 \mathrm{~K}$, dominated by the inverted bowl shape clearly seen in the image. This shape is due to the near-field condition of the anechoic chamber, not taken into account in the inversion process. The remaining error is due to the use of a simple imaging algorithm 


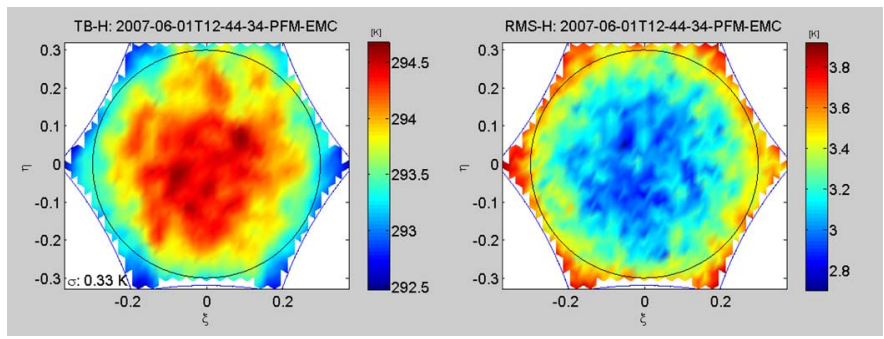

Fig. 19. (Left) Brightness temperature and (right) radiometric sensitivity of the empty chamber at H-polarization.

(fast Fourier transform) which does not include the measured G-matrix nor the fringe washing function. Furthermore, shown in the figure, at the right, is the map of radiometric sensitivity for 1.2-s integration time. At boresight, it is about $2.8 \mathrm{~K}$, consistent with theoretical expectations, and the increase for off-axis directions is due to the antenna pattern and obliquity factor, as predicted by the theory. Similar results are obtained for the V-polarization.

\section{ELECTROMAGNETIC COMPATIBILITy}

Electromagnetic compatibility tests were performed at the ESA's Maxwell anechoic chamber and also at Thales Alenia Space in Cannes (France), in this case with the instrument integrated to the platform. During the tests, the instrument was kept continuously in a specific measurement configuration during a long period of time at constant temperature. Different subsystems of the platform and the payload-such as thermal control heaters, star tracker, X-band and S-band transmitters, solar arrays, and others-were sequentially turned on in order to detect the RFI effects in correlations and/or PMS and to assess their impact on system performance.

\section{A. Methodology}

For comparison tests, a "Success Criteria Tool" was designed to compare the statistical properties of a reference measurement with those of measurements under perturbation in order to assess whether the variations between their statistics were below a certain threshold previously defined as the success criteria [26], [27]. The magnitudes to be compared in both tests (nominal and under perturbation) are complex correlations and power detector voltages when the instrument is measuring the anechoic chamber background. The following success criteria have been defined for the mean and standard deviation, respectively:

$$
\begin{aligned}
& \left|\operatorname{mean}\left(X_{\text {meas }}\right)-\operatorname{mean}\left(X_{\text {ref }}\right)\right|<\operatorname{std}\left(X_{\text {ref }}\right) \\
& \operatorname{std}\left(X_{\text {meas }}\right)<\operatorname{mean}\left[\operatorname{std}\left(X_{\text {ref }}\right)\right]+3 \operatorname{std}\left[\operatorname{std}\left(X_{\text {ref }}\right)\right]
\end{aligned}
$$

where $X_{\text {ref }}$ stands for the reference measurement and $X_{\text {meas }}$ stands for the same magnitudes in the case of the measurement under perturbation.

\section{B. Results}

As an example, in Fig. 20, the impact of the nominal X-band transmitter switching on is evaluated. The criteria given by (8) and (9) are shown in the left and right of the figure, respectively.
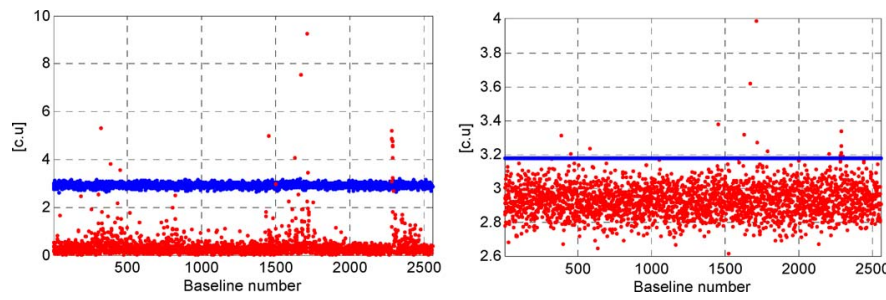

Fig. 20. Success criteria plot for the normalized complex correlations in nominal X-band transmitter during switching on test. H-polarization. Nominal test: X-band transmitter off. Measurement under perturbation: X-band transmitter on. (Left) Success criteria for the mean. (Right) Success criteria for the standard deviation. Marginal perturbations are detected both in the mean and the standard deviation.

The blue thick line of dots corresponds to the right-hand side of the equations while the sparse red dots are the left-hand side. The effects of switching the transmitter on in the correlations involving receivers close to it can be easily detected both in the mean (left) and in the standard deviation (right). These results are for $\mathrm{H}$-polarization and are different for $\mathrm{V}$-polarization, therefore indicating coupling at the antenna port. On the other hand, when using a second redundant transmitter included in the platform (not shown here; see [26]), no perturbations were seen.

The conclusion of all compatibility tests carried out shows that there is no other source of major interference nor with the platform nor with other subsystems of the payload. There is only this small interference from the X-band transmitter in nominal correlations during a short period of time. This last effect is not critical but it can be overcome, if needed, by using the instrument in redundant mode, for which there was no interference at all.

\section{CONCLUSION}

MIRAS has been successfully and extensively characterized on ground in terms of basic operation, thermal cycling, image validation, interelement phase, and RFI. The results have shown that the instrument performance is excellent, having all parameters according to specifications, except for an anomaly detected in the temperature dependence of the phase of correlation and a minor interference of the nominal X-band transmitter. The internal-calibration concept and operation has been validated, providing highly repeatable and accurate calibration parameters with low temperature sensitivity, which has also been derived. Absolute amplitude calibration has been demonstrated in the anechoic chamber measurements using the average of all PMS values, showing that the instrument can measure absolute brightness temperatures with an accuracy of $0.1 \mathrm{~K}$. The absolute residual correlation error has been shown to be negligible after compensating for correlator offsets, except for baselines sharing common circuits. Images of the brightness temperature of the empty chamber have shown radiometric accuracies of less than half of a kelvin and radiometric sensitivities according to the theoretical expectations as a function of integration time and bandwidth. These figures are far beyond the mission requirement of $4.1 \mathrm{~K}$ of radiometric accuracy and $3 \mathrm{~K}$ of radiometric sensitivity. 


\section{ACKNOWLEDGMENT}

The authors would like to thank the EADS-CASA Espacio team for their excellent work done in the preparation and execution of the tests, particularly A. Borges, the payload project manager, J. Benito, the person responsible for the tests, and $\mathrm{J}$. Closa, the engineer in charge of the measurements.

\section{REFERENCES}

[1] P. Silvestrin, M. Berger, Y. Kerr, and J. Font, "ESA's second Earth explorer opportunity mission: The Soil Moisture and Ocean Salinity mission-SMOS," IEEE Geosci. Remote Sens. Newslett., no. 118, pp. 11-14, Mar. 2001.

[2] Y. Kerr, P. Waldteufel, J.-P. Wigneron, J.-M. Martinuzzi, J. Font, and M. Berger, "Soil moisture retrieval from space: The Soil Moisture and Ocean Salinity (SMOS) mission," IEEE Trans. Geosci. Remote Sens., vol. 39, no. 8, pp. 1729-1735, Aug. 2001.

[3] J. Font, G. S. Lagerloef, D. M. Le Vine, A. Camps, and O.-Z. Zanifé, "The determination of surface salinity with the European SMOS space mission," IEEE Trans. Geosci. Remote Sens., vol. 42, no. 10, pp. 21962205, Oct. 2004

[4] H. Barré, B. Duesmann, and Y. Kerr, "SMOS. The mission and the system," IEEE Trans. Geosci. Remote Sens., vol. 46, no. 3, pp. 587-593, Mar. 2008.

[5] M. Martín-Neira and J. M. Goutoule, "MIRAS-A two-dimensional aperture-synthesis radiometer for soil moisture and ocean salinity observations," ESA Bull., no. 92, pp. 95-104, Nov. 1997.

[6] K. McMullan, M. Brown, M. Martín-Neira, W. Rits, S. Ekholm, J. Marti, and J. Lemanzyk, "SMOS: The payload," IEEE Trans. Geosci. Remote Sens., vol. 46, no. 3, pp. 594-605, Mar. 2008.

[7] C. S. Ruf, C. T. Swift, A. B. Tanner, and D. M. Le Vine, "Interferometric synthetic aperture microwave radiometry for the remote sensing of the Earth," IEEE Trans. Geosci. Remote Sens., vol. 26, no. 5, pp. 597-611, Sep. 1988.

[8] I. Corbella, N. Duffo, M. Vall-llossera, A. Camps, and F. Torres, "The visibility function in interferometric aperture synthesis radiometry," IEEE Trans. Geosci. Remote Sens., vol. 42, no. 8, pp. 1677-1682, Aug. 2004.

[9] I. Corbella, F. Torres, A. Camps, A. Colliander, M. Martín-Neira, S. Ribó, K. Rautiainen, N. Duffo, and M. Vall-llossera, "MIRAS end-toend calibration. Application to SMOS L1 processor," IEEE Trans. Geosci. Remote Sens., vol. 43, no. 5, pp. 1126-1134, May 2005.

[10] M. Brown, F. Torres, I. Corbella, and A. Colliander, "SMOS calibration," IEEE Trans. Geosci. Remote Sens., vol. 46, no. 3, pp. 646-658, Mar. 2008.

[11] I. Corbella, F. Torres, S. Blanch, S. Ribó, S. Beraza, N. Duffo, A. Camps, M. Vall-llossera, and M. Martín-Neira, "Inter-element phase calibration in interferometric radiometers," in Proc. IEEE IGARSS, Denver, CO, Jul. 31-Aug. 4 2006, pp. 3976-3979.

[12] A. Colliander, L. Ruokokoski, J. Suomela, K. Veijola, J. Kettunen, V. Kangas, A. Aalto, M. Levander, H. Greus, M. T. Hallikainen, and J. Lahtinen, "Development and calibration of SMOS reference radiometer," IEEE Trans. Geosci. Remote Sens., vol. 45, no. 7, pp. 1967-1977, Jul. 2007.

[13] J. Lemmetyinen, J. Uusitalo, J. Kainulainen, K. Rautiainen, N. Fabritius, M. Levander, V. Kangas, H. Greus, J. Pihlflyckt, A. Kontu, S. Kemppainen, A. Colliander, M. T. Hallikainen, and J. Lahtinen, "SMOS calibration subsystem," IEEE Trans. Geosci. Remote Sens., vol. 45, no. 11, pp. 3691-3700, Nov. 2007.

[14] I. Corbella, F. Torres, N. Duffo, V. González, A. Camps, and M. Vall-llossera, "Fast processing tool for SMOS data," in Proc. IEEE IGARSS, Boston, MA, Jul. 7-11, 2008, pp. II-1152-II-1155.

[15] M. Martín-Neira, S. Ribó, and K. Rautiainen, "0-1 correction of comparator threshold in 1-bit interferometric radiometers," in Proc. 8th Spec. Meeting Microw. Radiometry Remote Sens. Appl.- $\mu$ Rad, Feb. 24-27, 2004, p. 93.

[16] F. Torres, I. Corbella, A. Camps, N. Duffo, M. Vall-llossera, S. Beraza, C. Gutierrez, and M. Martín-Neira, "Denormalization of visibilities for in-orbit calibration of interferometric radiometers," IEEE Trans. Geosci. Remote Sens., vol. 44, no. 10, pp. 2679-2686, Oct. 2006.

[17] I. Corbella, F. Torres, A. Camps, N. Duffo, and M. Vall-llossera, "Brightness temperature retrieval methods in synthetic aperture radiometers," IEEE Trans. Geosci. Remote Sens., vol. 47, no. 1, pp. 285-294, Jan. 2009.
[18] M. Martín-Neira, M. Suess, and J. Kainulainen, "The flat target transformation," IEEE Trans. Geosci. Remote Sens., vol. 46, no. 3, pp. 613-620, Mar. 2008.

[19] V. González-Gambau, F. Torres, N. Duffo, and M. Martín-Neira, "Calibration consistency tool for interferometric radiometers," in Proc. IEEE IGARSS, Boston, MA, Jul. 7-11, 2008, pp. V-401-V-404.

[20] J. Bará, A. Camps, I. Corbella, and F. Torres, "The specification of channel filters for an interferometric radiometer," Radio Sci., vol. 36, no. 1, pp. 97-106, Feb. 2001.

[21] M. Martín-Neira, S. Ribó, and A. J. Martín-Polegre, "Polarimetric mode of MIRAS," IEEE Trans. Geosci. Remote Sens., vol. 40, no. 8, pp. 17551768, Aug. 2002.

[22] I. Corbella, F. Torres, A. Camps, J. Bará, N. Duffo, and M. Vall-llossera, "L-band aperture synthesis radiometry: Hardware requirements and system performance," in Proc. IEEE IGARSS, Honolulu, HI, Jul. 24-28, 2000, vol. 7, pp. 2975-2977.

[23] F. Torres, V. González-Gambau, and C. González-Haro, "One-point calibration in interferometric radiometers devoted to Earth observation," in Proc. SPIE Eur. Remote Sens. Sensors, Syst., Next-Generation Satellites XII, Cardiff. Wales, U.K., Sep. 15-18, 2008.

[24] P. Moreno-Galbis, J. Kainulainen, and M. Martín-Neira, "Experimental demonstration of the Corbella equation for aperture synthesis microwave radiometry," IEEE Trans. Geosci. Remote Sens., vol. 45, no. 4, pp. 945957, Apr. 2007.

[25] A. Colliander, M. Martin-Neira, J. Closa, and J. Benito, "Pre launch sensitivity estimation of SMOS zero-baseline radiometer in anechoic chamber," IEEE Trans. Geosci. Remote Sens., submitted for publication.

[26] V. González-Gambau, F. Torres, F. J. Benito, J. Closa, and M. Martín-Neira"Analysis of EMC tests for interferometric radiometers," in Proc. SPIE Eur. Remote Sens. Sensors, Syst., Next-Generation Satellites XII, Cardiff. Wales, U.K., Sep. 15-18, 2008.

[27] V. González-Gambau, F. Torres, F. J. Benito, J. Closa, and M. Martín-Neira, "Success criteria tool in EMC tests for interferometric radiometers," in Proc. IEEE IGARSS, Boston, MA, Jul. 7-11, 2008, pp. V-409-V-412.

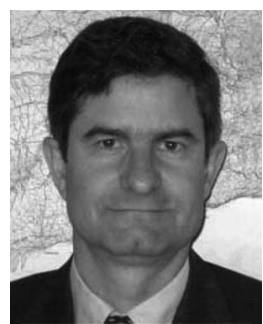

Ignasi Corbella (M'99-SM'08) received the Telecommunication Engineer and Dr.Eng. degrees from the Universitat Politècnica de Catalunya (UPC), Barcelona, Spain, in 1977 and 1983, respectively.

In 1976, he was with the School of Telecommunication Engineering, UPC, as a Research Assistant with the Microwave Laboratory, where he worked on passive microwave integrated-circuit design and characterization. In 1979, he was with ThomsonCSF, Paris, France, where he worked on microwave oscillator design. In 1982, he was an Assistant Professor, in 1986, an Associate Professor, and in 1993, a Full Professor with UPC, where he is currently teaching basic microwaves and antennas at the undergraduate level and graduate courses on nonlinear microwave circuits with the Remote Sensing Laboratory, Department of Signal Theory and Communications, where he was the Director from 2001 to 2003. Since 1993, he has been actively participating as a Researcher with the European Space Agency (ESA) Soil Moisture and Ocean Salinity (SMOS) mission in the frame of several contracts, directly with ESA or with the payload prime contractor European Aeronautic Defence and Space Company N.V.-Casa Espacio. His expertise includes, among others, the fundamentals of interferometric aperture synthesis radiometry, image reconstruction algorithms, onboard calibration, hardware specification, and payload characterization. From 1993 to 1997, he was an Academic Director of the School of Telecommunications Engineering, UPC. From 1998 to 1999, he was with the National Oceanic and Atmospheric Administration/Environmental Technology Laboratory, Boulder, $\mathrm{CO}$, as a Guest Researcher developing methods for totalpower radiometer calibration and data analysis. From 1999 to 2007, he was the Scientific Coordinator of a Dictionary of Telecommunication terms in Catalan language, with more than 4000 entries, published in March 2007. Since 2004, he has been a member of the SMOS Science Advisory Group, and since 2007, he has been a member of the SMOS Barcelona Expert Centre on Radiometric Calibration and Ocean Salinity, Barcelona.

Dr. Corbella was the General Chairman of the 2007 International Geoscience and Remote Sensing Symposium, Barcelona, from July 22-27, 2007. 


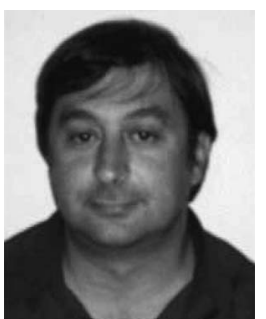

Francesc Torres (S'88-M'96-SM'06) was born in Ibiza, Spain, in 1962. He received the Ingeniero and Doctor Ingeniero degrees in telecommunication engineering from the Universitat Politècnica de Catalunya (UPC), Barcelona, Spain, in 1988 and 1992, respectively.

From 1988 to 1989, he was a Research Assistant with the RF System Division, European Space Agency, Noordwijk, The Netherlands, where he was devoted to microwave device testing and characterization. From 1989 to 1996, he was an Assistant Professor of microwave circuits and systems with the Remote Sensing Laboratory, Department of Signal Theory and Communications, UPC, where he has been an Associate Professor since 1996. From 2005 to 2006, he held a sabbatical stage with the Microwave Systems Section, Jet Propulsion Laboratory, Pasadena, CA, where he was involved in the GeoSTAR pilot project, which is a passive microwave interferometric geosounder. Since 1995, he has been participating in a number of projects related to the Soil Moisture and Ocean Salinity (SMOS) mission by the European Space Agency. He is currently coleading the SMOS Barcelona Expert Centre on Radiometric Calibration and Ocean Salinity, Barcelona.

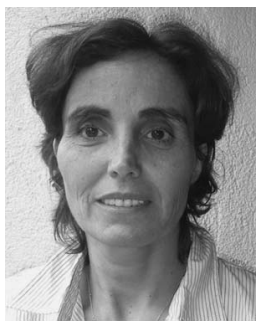

Nuria Duffo (S'91-M'95) received the B.S. and $\mathrm{Ph} . \mathrm{D}$. degrees in telecommunication engineering from the School of Telecommunications Engineering, Universitat Politècnica de Catalunya (UPC), Barcelona, Spain, in 1990 and 1996, respectively.

Since 1997, she has been an Associate Professor with the Remote Sensing Laboratory, Department of Signal Theory and Communications, UPC. Her current research activities include numerical methods in electromagnetics, microwave radiometry, antenna analysis, and design.

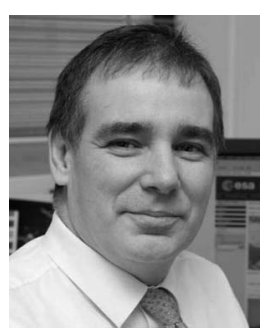

Manuel Martín-Neira (M'96-SM'07) received the M.S. and Ph.D. degrees in telecommunication engineering from the School of Telecommunication Engineering, Universitat Politècnica de Catalunya, Barcelona, Spain, in 1986 and 1996, respectively.

From 1989 to 1992, he was with GMV, a Spanish firm, where he was responsible for several projects for the European Space Agency (ESA), Noordwijk, The Netherlands, related to global positioning satellite navigation with applications to precise landing and attitude determination. Since 1992, he has been with ESA, Paris, France, where he is in charge of the radiometer activities within the Payload, Equipment, and Technology Section and where he is currently a Soil Moisture and Ocean Salinity Instrument Principal Engineer. During this period, he has been responsible for the technology activities related to the Microwave Imaging Radiometer with Aperture Synthesis project.

Dr. Martín-Neira was the recipient of a fellowship to work on radiometry at the European Space Research and Technology Center, Noordwijk, The Netherlands, in 1988 .

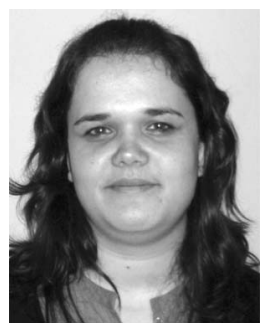

Verónica González-Gambau was born in Huesca, Spain. She received the Telecommunication Engineer degree from the Universitat Politècnica de Catalunya (UPC), Barcelona, Spain, in 2006, where, after it, she joined the Passive Remote Sensing Group, Remote Sensing Laboratory, Department of Signal Theory and Communications, where she is currently working toward the Ph.D. degree.

She has been involved in Microwave Imaging Radiometer with Aperture Synthesis (MIRAS)-Soil Moisture and Ocean Salinity (SMOS) demonstrator test campaigns in the framework of the MIRAS Demonstrator Pilot Project-3 and in the SMOS Image Validation Test campaigns in the framework of SMOS Precommissioning activities. She has been collaborating with the software development and data analysis of the MIRAS instrument validation campaigns. Her current research activities are related to SMOS level 1A data processing. Since 2007, she has been a member of the SMOS Barcelona Expert Centre on Radiometric Calibration and Ocean Salinity, Barcelona.

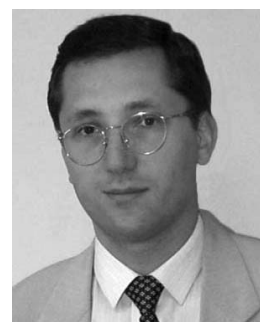

Adriano Camps (S'91-A'97-M'00-SM'03) was born in Barcelona, Spain, in 1969. He received the B.S. and Ph.D. degrees in telecommunications engineering from the Universitat Politècnica de Catalunya (UPC), Barcelona, in 1992 and 1996, respectively.

In 1991-1992, he was with the École Nationale Supérieure des Télécommunications de Bretagne, Brest, France, with an Erasmus fellowship. In 1993, he joined the Electromagnetic and Photonics Engineering Group, Department of Signal Theory and Communications, UPC, as an Assistant Professor, where he became an Associate Professor in 1997 and where has been a Full Professor since 2007 with the Remote Sensing Laboratory. In 1999, he was on sabbatical leave at the Microwave Remote Sensing Laboratory, University of Massachusetts, Amherst. His research interests are focused on microwave remote sensing, with special emphasis on microwave radiometry by aperture synthesis techniques. He has performed numerous studies within the frame of the European Space Agency Soil Moisture and Ocean Salinity Earth Explorer Mission, which have received several awards. He is the Associate Editor of Radio Science.

Dr. Camps was the Chair of $\mu \mathrm{Cal} 2001$ and the Technical Program Committee Chair of the International Geoscience and Remote Sensing Symposium 2007. He was the recipient of the second national award of university studies in 1993, the INDRA award of the Spanish Association of Telecommunication Engineering to the best Ph.D. in Remote Sensing in 1997, the extraordinary Ph.D. award at UPC in 1999, the Research Distinction of the Generalitat de Catalunya for contributions to microwave passive remote sensing in 2002, and the European Young Investigator Award in 2004 from the European Science Foundation. In addition, as a member of the Microwave Radiometry Group at UPC, he was the recipient, in 2000, 2001, and 2004, of the First Duran Farell and the Ciudad de Barcelona awards for Technology Transfer and of the "Salvà I Campillo" Award of the Professional Association of Telecommunication Engineers of Catalonia for the most innovative research project, respectively. From 2003 to 2006, he was an Editor of the IEEE Geoscience and Remote Sensing Newsletter, of which he is currently the Associate Editor. He is the President-Founder of the IEEE Geoscience and Remote Sensing Society Chapter, Spain.

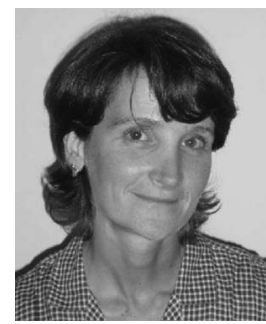

Mercè Vall-llossera (M'99) received the Senior Telecommunication Engineering degree and the $\mathrm{Ph} . \mathrm{D}$. degree in telecommunication engineering from the Universitat Politecnica de Catalunya (UPC), Barcelona, Spain, in 1990 and 1994, respectively.

She has been lecturing and doing research with the Department of Signal Theory and Communications, UPC, as an Assistant Professor from 1990 to 1997 and as an Associate Professor since 1997 in the Remote Sensing Laboratory. She spent a sabbatical year with the University of Concordia, Montreal, Canada, with the scholarship of the "Programme Quebecois de Bourses d'excellence (1996-1997): Stages de Formation postdoctorale au Quebec pour jeunes diplomes etrangers." Her research activities are numerical methods in electromagnetics, microwave radiometry, antenna analysis, and design. Currently, her research is mainly related to the study of numerical methods applied to sea surface emissivity and their characterization at L-band and the Microwave Imaging Radiometer with Aperture Synthesis/Soil Moisture and Ocean Salinity project.

Dr. Vall-llossera was the recipient of the "Primer Premio Duran Farell de Investigación Tecnológica," with the other member of the Radiometry Group at UPC, in 2000, and the "Primer Premio Ciutat de Barcelona d'Investigació Tecnòlogica," in 2001. 